\title{
Circadian Rhythms in the Suprachiasmatic Nucleus are Temperature-Compensated and Phase-Shifted by Heat Pulses In Vitro
}

\author{
Norman F. Ruby, D. Erik Burns, and H. Craig Heller \\ Department of Biological Sciences, Stanford University, Stanford, California 94305
}

Temperature compensation and the effects of heat pulses on rhythm phase were assessed in the suprachiasmatic nucleus (SCN). Circadian neuronal rhythms were recorded from the rat SCN at 37 and $31^{\circ} \mathrm{C}$ in vitro. Rhythm period was $23.9 \pm 0.1$ and $23.7 \pm 0.1 \mathrm{hr}$ at 37 and $31^{\circ} \mathrm{C}$, respectively; the $Q_{10}$ for tau was 0.99 . Heat pulses were administered at various circadian times (CTs) by increasing SCN temperature from 34 to $37^{\circ} \mathrm{C}$ for $2 \mathrm{hr}$. Phase delays and advances were observed during early and late subjective night, respectively, and no phase shifts were obtained during midsubjective day. Maximum phase delays of $2.2 \pm 0.3 \mathrm{hr}$ were obtained at CT 14 , and maximum phase advances of $3.5 \pm 0.2 \mathrm{hr}$ were obtained at CT 20. Phase delays were not blocked by a combination of NMDA [AP-5 (100 $\mu \mathrm{M})$ ] and non-NMDA [CNQX $(10 \mu \mathrm{M})$ ] receptor antagonists or by

Temperature and light have similar effects on circadian organization across a wide range of species. Phase response curves (PRCs) to light and heat pulses are generally similar in plants (Wilkins, 1983), fungi (Francis and Sargent, 1979; Nakashima, 1987), single-cell organisms (Njus et al., 1977), insects (Zimmerman et al., 1968; Edery et al., 1994), and birds (Barrett and Takahashi, 1995). Although light and temperature work synergistically in nature, light is generally considered a more potent entraining agent (i.e., zeitgeber) than temperature. In the circadian systems of some lower organisms, however, temperature can be the dominant zeitgeber when the phase relationship between these zeitgebers is altered (Underwood, 1990; Liu et al., 1998). Despite the potent effects of temperature on circadian rhythms in ectotherms, little work has been done in endotherms. This disparity exists largely because it is assumed that the relatively narrow range of temperatures experienced by circadian pacemakers in homeotherms has little consequence for circadian organization. This assumption fails to consider, however, that the evolution of endothermy may have relaxed selection pressure for temperature compensation of pacemaker frequency and for pacemaker sensitivity to phase shifts by thermal stimuli.

The effects of temperature on circadian rhythms have been very difficult to test in homeothermic mammals in vivo because pacemaker temperature is homeostatically controlled within nar-

\footnotetext{
Received Feb. 4, 1999; revised July 7, 1999; accepted July 19, 1999.

This work was supported by Grant HD37315 from National Institute of Child Health and Human Development. We thank Joseph D. Miller for comments on an earlier version of this manuscript.

Portions of these data were presented at the Society for Research on Biological Rhythms, 1998.

Correspondence should be addressed to Norman F. Ruby, Department of Biological Sciences, Stanford University, Stanford, CA 94305-5020.

Copyright (C) 1999 Society for Neuroscience 0270-6474/99/198630-07\$05.00/0
}

tetrodotoxin (TTX) at concentrations of 1 or $3 \mu \mathrm{m}$. The phase response curve for heat pulses is similar to ones obtained with light pulses for behavioral rhythms. These data demonstrate that circadian pacemaker period in the rat SCN is temperaturecompensated over a physiological range of temperatures. Phase delays were not caused by activation of ionotropic glutamate receptors, release of other neurotransmitters, or temperature-dependent increases in metabolism associated with action potentials. Heat pulses may have phase-shifted rhythms by directly altering transcriptional or translational events in SCN pacemaker cells.

Key words: suprachiasmatic; circadian; temperature compensation; phase shift; phase response curve; single unit; electrophysiology; glutamate; tetrodotoxin; AP-5; CNQX row limits. Some studies have addressed this issue in rodents by making them hypothermic (Rawson, 1960; Gibbs, 1981, 1983); although circadian rhythm period was found to be temperaturecompensated, the extreme measures used to lower core temperature make it difficult to interpret those findings. Entrainment of activity rhythms to ambient temperature $\left(T_{\mathrm{a}}\right)$ cycles has been reported for rats (Francis and Coleman, 1988), antelope ground squirrels (Pohl, 1998), bats (Erkert and Rothmund, 1981), Syrian hamsters (Pohl, 1998), blind mole rats (Goldman et al., 1997), marsupial mice (Francis and Coleman, 1990), and some primates (Tokura and Aschoff, 1983; Aschoff and Tokura, 1986). Furthermore, heat pulses of $T_{\mathrm{a}}$ can phase-shift activity rhythms in rats (Francis and Coleman, 1997) and pocket mice (Lindberg and Hayden, 1974). Temperature also affects tau; decreases in $T_{\mathrm{a}}$ can shorten tau by $>45 \mathrm{~min}$ in pig-tailed macaques (Tokura and Aschoff, 1983), but have no effect in squirrel monkeys (Aschoff and Tokura, 1986). Although the temperature effects in all of these studies were modest, they demonstrate that the mammalian circadian system has retained some sensitivity to thermal stimuli.

The hypothalamic suprachiasmatic nucleus (SCN) confers circadian organization to a wide range of behavioral and physiological events in mammals (Rusak and Zucker, 1979; Rosenwasser, 1988). The effects of temperature on tau and entrainment are, therefore, the result of either thermal afferent input to the SCN or changes in SCN temperature. None of the aforementioned studies in mammals monitored brain temperature $\left(T_{\mathrm{br}}\right)$; thus it is unclear how those treatments affected the SCN. One goal of this study was to determine whether the $\mathrm{SCN}$ would respond to temperature changes as do circadian pacemakers in lower organisms. Temperature compensation is a functional prerequisite for circadian pacemakers (Pittendrigh, 1960); however, this feature of circadian organization has not been demonstrated in the SCN 
of homeotherms. Thus, a second goal of this study was to test whether circadian neuronal rhythms in the rat SCN are temperature-compensated. We found that heat pulses phase-shift SCN rhythms in a manner similar to light pulses; therefore, we also tested whether these phase shifts were caused by activation of photic signal transduction pathways or changes in metabolic rate, or whether they required neuronal interactions among SCN neurons.

\section{MATERIALS AND METHODS}

Brain slice preparation and maintenance. Adult male Wistar rats (Simonsen) were housed in the laboratory in a $12 \mathrm{hr}$ light/dark (LD) cycle (fluorescent lights on at 8:00 A.M., pacific standard time) at an ambient temperature $\left(T_{\mathrm{a}}\right)$ of $22^{\circ} \mathrm{C}$. Food and water were available ad libitum. All brain slices were prepared within $1 \mathrm{hr}$ after lights on in the animal room. After rapid decapitation, the optic tracts were severed, and brains were quickly removed. The hypothalamic region was then blocked, and 500 $\mu \mathrm{m}$ coronal slices were prepared on a tissue chopper (Sorvall). Tissue slices containing the paired SCN, optic chiasm, and minimal surrounding tissue were incubated in a Hatton-style brain slice chamber (Hatton et al., 1980) warmed to either 37,34 , or $31^{\circ} \mathrm{C}$ and gassed continuously with $95 \% \mathrm{O}_{2}$ and $5 \% \mathrm{CO}_{2}$. Brain slices were allowed at least $1 \mathrm{hr}$ to equilibrate before electrical recording.

Calibration of the temperature in the tissue slice chamber was accomplished by inserting a thin wire thermocouple that was connected to a digital thermometer (Sensortek) into a tissue slice in an area dorsal to the SCN (Ruby and Heller, 1996). The slice chamber was then closed around the thermocouple, and water bath temperature was adjusted to maintain the brain slice precisely either at 37,34 , or $31^{\circ} \mathrm{C}$. The temperature of the slice chamber was monitored periodically in experimental trials. Tissue slices were continuously perfused at $35 \mathrm{ml} / \mathrm{hr}$ with Earle's Balanced Salt Solution (Sigma, St. Louis, MO) supplemented with $24.6 \mathrm{~mm}$ glucose and $26.2 \mathrm{~mm}$ sodium bicarbonate, $\mathrm{pH}$ 7.4. For tissue slices maintained longer than $36 \mathrm{hr}$, the medium was supplemented with an antibiotic $(0.05 \%$ gentamicin). Under these conditions, the SCN remain viable and exhibit robust circadian rhythms in spontaneous neuronal activity for at least 60 hr (Gillette, 1991; Ruby and Heller, 1996).

Electrophysiological recording. Extracellular recordings from single cells were made using glass microelectrodes filled with $3 \mathrm{~m} \mathrm{NaCl}$. The electrode was lowered into the SCN with a hydraulic microdrive until action potentials were observed. Spikes with amplitudes at least twice that of background noise were observed for $2 \mathrm{~min}$ to verify that firing patterns were stable; only cells with stable firing rates and amplitudes were recorded. After the firing rate of a cell was recorded for $5 \mathrm{~min}$, the electrode was advanced until another cell was encountered. The repetition of this process over $8-15 \mathrm{hr}$ constituted a recording trial. Each electrode track in the SCN was placed randomly, and cells were recorded throughout the cross-sectional extent of each SCN. All data were stored on computer for subsequent analysis (DataWave).

Drugs. Tetrodotoxin (TTX) was applied at a concentration of $1 \mu \mathrm{M}$ because this concentration blocks sodium-dependent action potentials in the SCN and other preparations (Hille, 1992; Walsh et al., 1992; Shibata and Moore, 1993). TTX was also applied at a concentration of $3 \mu \mathrm{M}$ for comparison because low-amplitude potentials have been detected in cultured neurons by whole-cell recording in the presence of $1 \mu \mathrm{M}$ TTX (Belousov and van den Pol, 1997). NMDA [AP-5 (100 $\mu \mathrm{M})]$ and nonNMDA [CNQX $(10 \mu \mathrm{M})]$ receptor antagonists were applied together at these concentrations to block ionotropic glutamate receptor activation (Belousov and van den Pol, 1997). All drugs (Sigma) were frozen $\left(-20^{\circ} \mathrm{C}\right)$ in $1000 \times$ aliquots until $15 \mathrm{~min}$ before use.

Experimental protocol. Tissue slices were maintained at either 37 or $31^{\circ} \mathrm{C}$ for temperature compensation experiments or at $34^{\circ} \mathrm{C}$ for heat pulse experiments. Phase shifts were accomplished by increasing the temperature of the bathing medium on day one in vitro until tissue temperature reached $37^{\circ} \mathrm{C}$ and then returned to $34^{\circ} \mathrm{C}$ at the end of the pulse. Heat pulses were applied such that the midpoint of the pulse occurred $2,5,8,11,14,16,18,20$, or $23 \mathrm{hr}$ after the time of lights on in the donor colony, regardless of the duration of the pulse. Cells were recorded on either the following day or on day 3 in vitro. Each drug was applied to the tissue $15 \mathrm{~min}$ before the start of the heat pulse by stopping the flow of medium and rapidly $(<2 \mathrm{~min})$ removing the medium from the chamber that surrounds the tissue slice and replacing it with the same medium containing TTX or AP-5/CNQX. Flow was resumed with me-

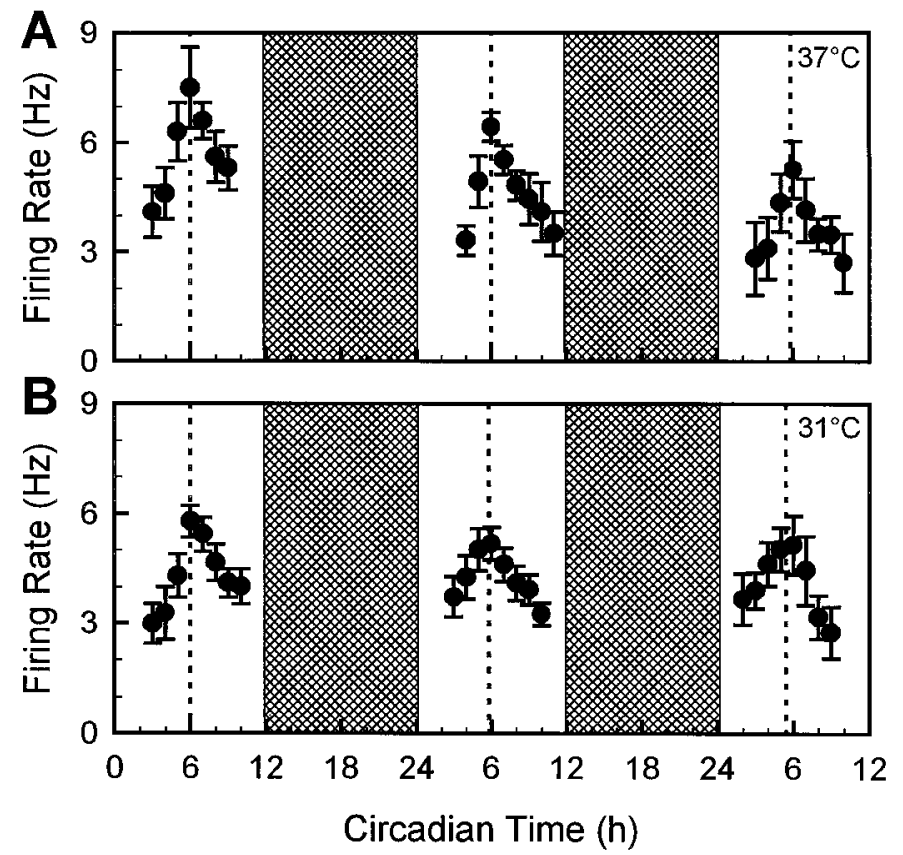

Figure 1. Representative recordings at $37^{\circ} \mathrm{C}(A)$ and $31^{\circ} \mathrm{C}(B)$; each of the six recordings is from a different animal. Each point is the mean $( \pm \mathrm{SE}$ ) hourly firing rate of $10-12 \mathrm{SCN}$ neurons. Circadian time 0 is the time of lights on in the donor colony; all tissue slices were prepared between CT 0 and $1 \mathrm{hr}$ on day 1 . Shaded areas represent projected dark phases of the LD cycle in the donor colony (LD 12/12). Vertical dashed lines represent the mean time of peak firing rates at each temperature on each day. The $Q_{10}$ for tau was 0.99 .

dium containing the drug until 15 or 45 min after the end of the heat pulse. Medium containing the drug was then rapidly $(<2 \mathrm{~min}$ ) replaced with standard bath medium, and tissue perfusion resumed. Data from both drug termination times did not differ and were combined.

Data analysis. The average firing rate of each cell was determined by calculating the reciprocal of its mean interspike interval. Mean $( \pm$ SE) hourly firing rates were calculated by a running average with a $2 \mathrm{hr}$ window and $1 \mathrm{hr}$ lag (Gillette, 1991; Ruby and Heller, 1996). Peak neuronal firing rate was defined as the single highest hourly value obtained on the day of recording. Circadian time 0 was defined as the time of lights on in the donor colony on day 1 and the projected time of lights on for days 2 and 3 . Circadian rhythm phase was defined as the time of peak firing rate (hr) relative to CT 0 (e.g., CT $6=6 \mathrm{hr}$ after lights on). Time of peak firing rate has been used extensively as a reliable index of circadian pacemaker phase (Gillette, 1991). Phase shifts are expressed as the difference between the mean times of peak firing rates in different treatment groups. Tau was defined as the average interval between daily peaks in firing rate. The effects of temperature on tau and firing rate were assessed by calculating $Q_{10}$ values at 37 and $31^{\circ} \mathrm{C}$. Differences among groups in peak firing rates were determined by two-way ANOVA or $t$ tests where appropriate. The relationship between heat pulse duration and phase-shift magnitude was evaluated by Pearson's correlation coefficient.

\section{RESULTS}

\section{Temperature compensation of neuronal rhythms}

Circadian neuronal rhythms were robust on all three days at both 37 and $31^{\circ} \mathrm{C}$ (Fig. 1). There were no significant differences in the times of peak firing rates on successive days $\left(F_{(2,11)}=0.78 ; p>\right.$ 0.05 ; Table 1) or at either tissue temperature on the same day $\left(F_{(1,11)}=1.10 ; p>0.05\right.$; Table 1$)$. To increase the temporal resolution of our results, these data were reanalyzed with a $2 \mathrm{hr}$ window and 20 min lag to obtain mean firing rates in $20 \mathrm{~min}$ intervals. There were no significant differences in the times of peak firing rates between these two methods $(p>0.05)$. The 


\begin{tabular}{|c|c|c|c|}
\hline Parameter & $37^{\circ} \mathrm{C}$ & $31^{\circ} \mathrm{C}$ & $\mathrm{Q}_{10}$ \\
\hline \multicolumn{4}{|l|}{ Rhythm phase $^{a}$} \\
\hline Peak day 1 & $6.0 \pm 0.0(2)$ & $6.0 \pm 0.0(2)$ & \\
\hline Peak day 2 & $6.0 \pm 0.4(4)$ & $5.8 \pm 0.3(4)$ & \\
\hline Peak day 3 & $5.8 \pm 0.3(3)$ & $5.4 \pm 0.3(4)$ & \\
\hline \multicolumn{4}{|c|}{ Peak firing rate ${ }^{b}$} \\
\hline Peak day 1 & $7.4 \pm 0.1(2)$ & $5.4 \pm 0.2(2)^{*}$ & 1.76 \\
\hline Peak day 2 & $6.1 \pm 0.6(3)^{* *}$ & $5.3 \pm 0.5(4)^{*}$ & 1.26 \\
\hline Peak day 3 & $4.7 \pm 0.5(3)^{* *}$ & $4.4 \pm 0.3(4)$ & 1.11 \\
\hline
\end{tabular}

${ }^{a}$ Mean $( \pm \mathrm{SE})$ time (hr) of peak firing rate; CT 0 represents the projected times of lights-on in the animal colony. Numbers of trials are in parentheses.

${ }^{b}$ Mean $( \pm \mathrm{SE})$ peak firing rates from multiple recording trials.

${ }^{*} p<0.01$ compared to same day values at $37^{\circ} \mathrm{C}$; ${ }^{* *} p<0.01$ compared to peak day 1 at $37^{\circ} \mathrm{C}$.

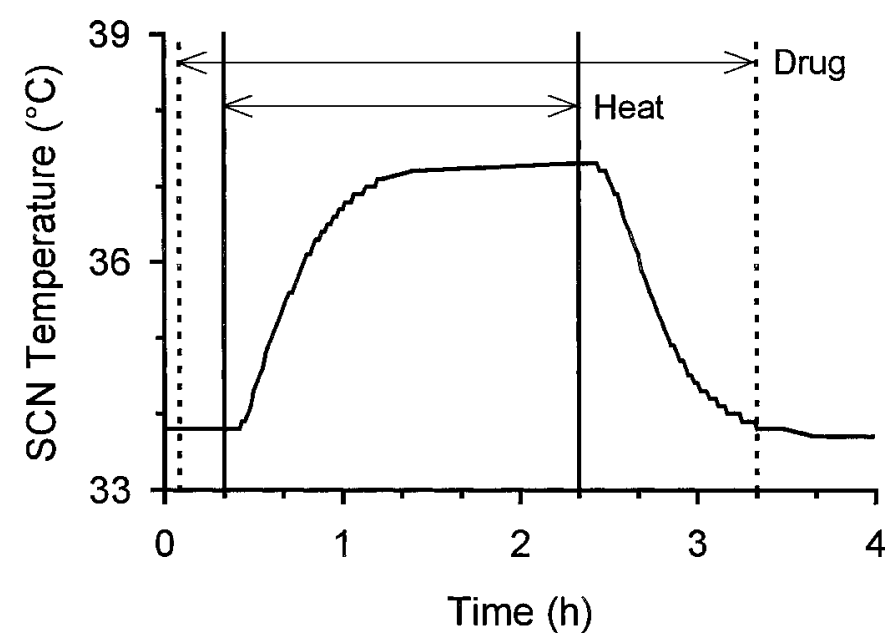

Figure 2. SCN temperature during a representative heat pulse. Solid vertical lines indicate the start and end times of the heat pulse. Dashed vertical lines indicate the start and end times of drug administration. Data are plotted in 5 min intervals.

average interval between daily peaks was $23.9 \pm 0.1$ and $23.7 \pm$ $0.1 \mathrm{hr}$ at 37 and $31^{\circ} \mathrm{C}$, respectively $(p>0.05)$. The $Q_{10}$ for tau over this temperature range was 0.99 .

Peak firing rates were significantly lower at 31 compared to $37^{\circ} \mathrm{C}\left(F_{(1,11)}=12.4 ; p<0.01\right.$; Table 1$)$; however, by day 3 there was no significant effect of temperature on peak firing rate $(p>$ 0.05 ; Table 1). There was a steady significant decline in peak firing rate on successive days at $37\left(F_{(2,5)}=5.76 ; p<0.05\right.$; Table $1)$ but not at $31^{\circ} \mathrm{C}(p>0.05) . Q_{10}$ for peak firing rate was 1.76 on day 1 and declined on successive days (Table 1 ).

\section{Heat pulse phase shifts}

A $3^{\circ} \mathrm{C}$ increase or decrease in SCN temperature was accomplished within $\sim 45$ min (Fig. 2). Heat pulses that were $2 \mathrm{hr}$ in duration produced phase shifts as great as $4 \mathrm{hr}$ during subjective night but had little or no effect during subjective day (Fig. 3). Phase shifts were stable with no difference in the times of peak firing rates on days 2 and 3 (Fig. 4; Table 1). Heat pulses produced a PRC that was similar to photic PRCs. Phase delays and advances were obtained during early and late subjective night, respectively (Fig. 5A). There was a linear relationship between
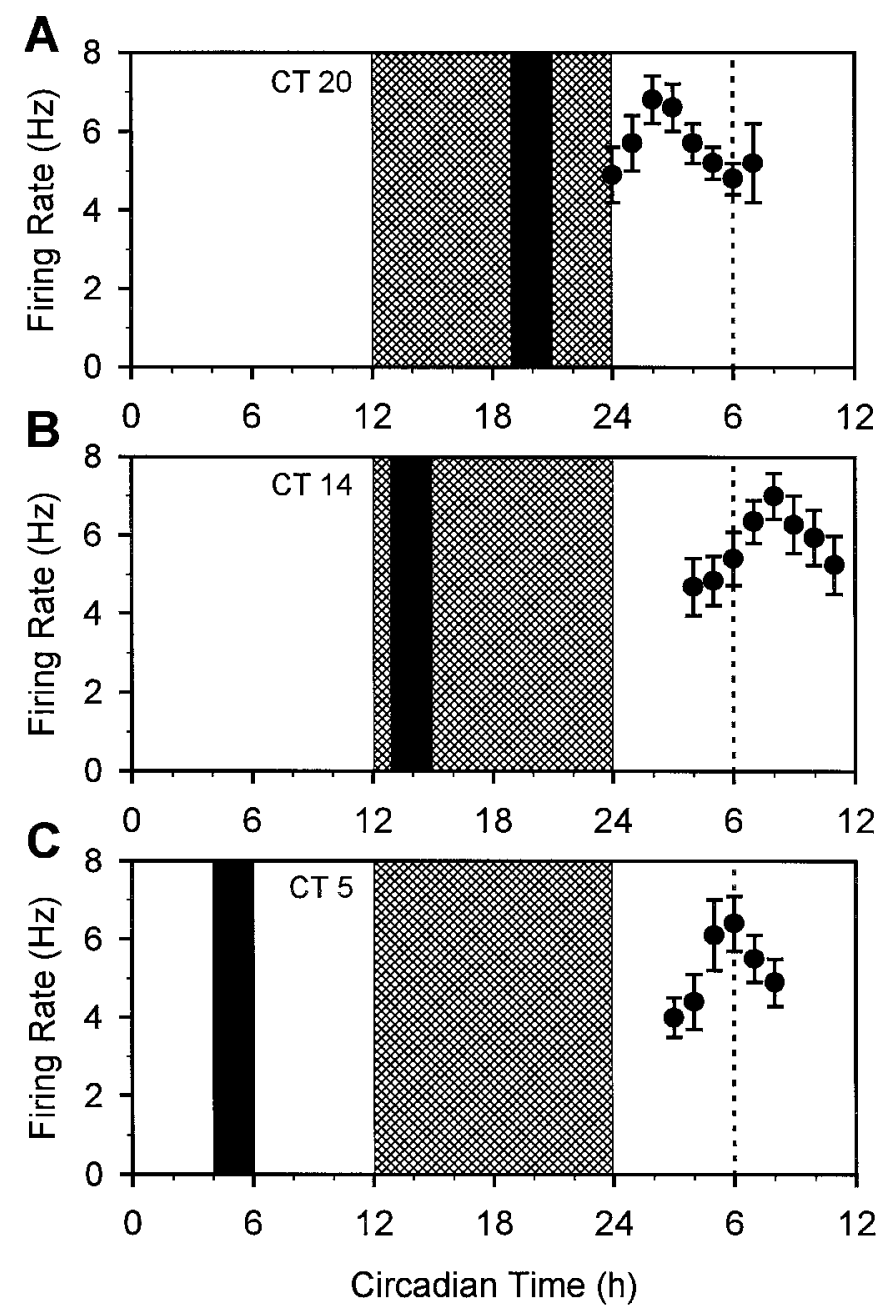

Figure 3. Representative recording trials in which tissue slices were heat-pulsed at CT $20(A), 14(B)$, or $5(C)$. Vertical black bars indicate time of heat pulse. Other symbols as in Figure 1.

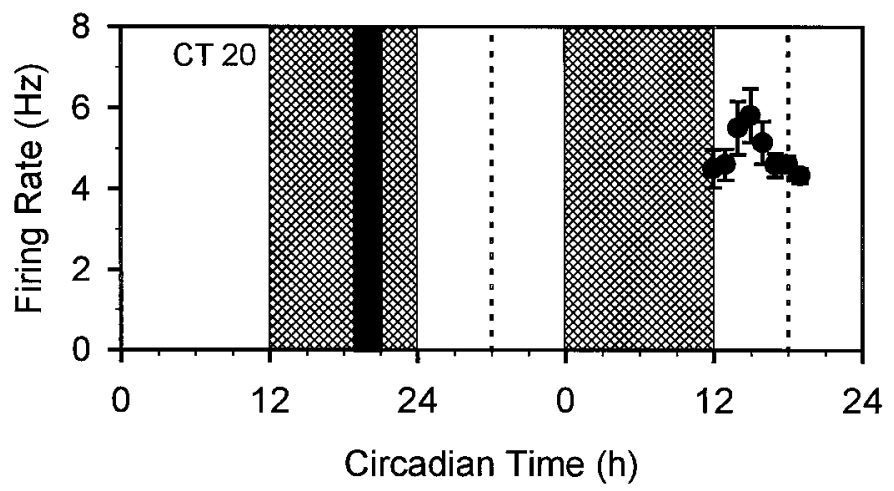

Figure 4. Representative recording from one tissue slice obtained on day 3 after a heat pulse was administered at CT 20 on day 1 . Time of peak firing rate was advanced by $3 \mathrm{hr}$. Vertical black bar indicates time of heat pulse. Other symbols as in Figure 1.

heat pulse duration at CT 14 and magnitude of phase shifts $(r=$ $0.95 ; p<0.0001$; Fig. $5 B)$. In contrast, increases in tissue temperature to $38^{\circ} \mathrm{C}$ did not further increase phase shifts obtained with a $2 \mathrm{hr}$ heat pulse (data not illustrated). 

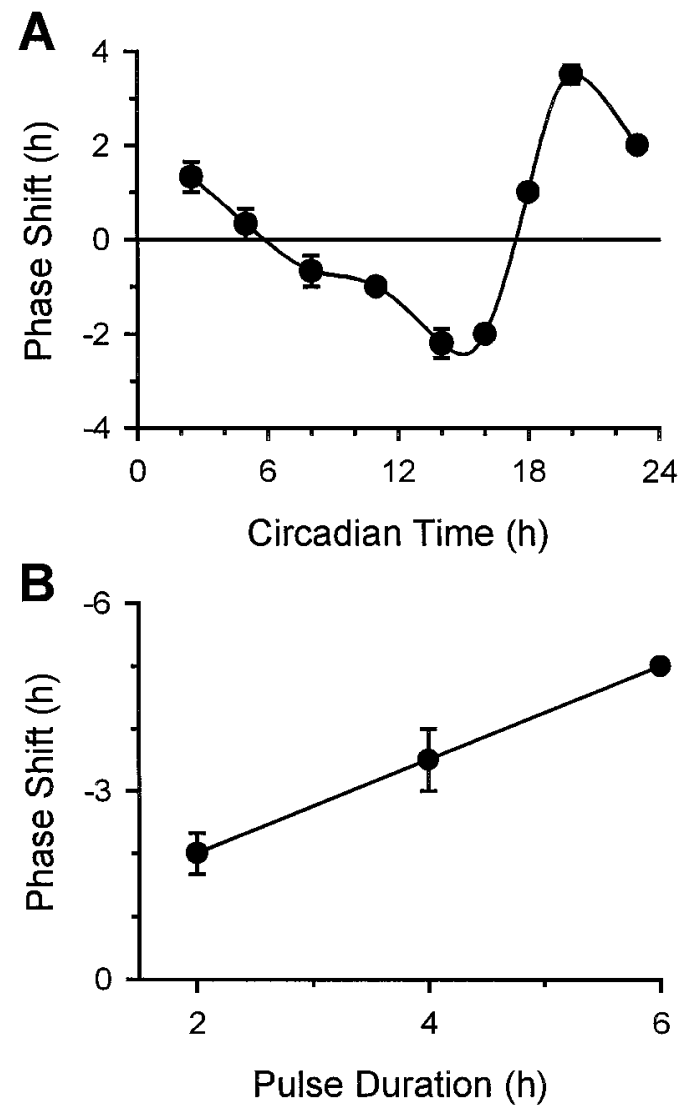

Figure 5. Phase response curve to heat pulses in which tissue temperature was increased from 34 to $37^{\circ} \mathrm{C}$ for $2 \mathrm{hr}$; data are plotted at the midpoint of each pulse $(A)$. Each symbol is the mean $( \pm \mathrm{SE})$ of three to six trials, except at CTs 16 and $18(n=2$ each). Maximal phase delays and advances were obtained with heat pulses applied in early and late, respectively, subjective night. Significant phase shifts were not obtained during most of subjective day (CT $0-12$ ). Note that this curve closely resembles a photic phase response curve. Phase-shift magnitude increased linearly with pulse durations $(B)$ of $2(n=6), 4(n=2)$, or $6(n=2)$ hr; solid line, first order regression $(r=0.95 ; p<0.0001)$.

\section{Effects of TTX and AP-5/CNQX on phase delays}

Rhythm phase of SCN slices treated with TTX $(1 \mu \mathrm{M} ; n=2)$ or AP-5/CNQX $(n=2)$ alone did not differ from the phase of untreated slices ( $p>0.05$; Fig. 6). Neither dose of TTX $(n=5)$ or application of AP-5/CNQX $(n=3)$ blocked heat pulseinduced phase delays at CT 14 (Fig. 7). There were no significant differences in the mean $( \pm \mathrm{SE})$ phase shifts produced by coapplication of the drugs with the heat pulse compared to phase shifts obtained by the heat pulse alone ( $p>0.05$; Fig. 6$)$.

\section{DISCUSSION}

Circadian neuronal rhythm period in the rat $\mathrm{SCN}$ is temperaturecompensated at temperatures within the physiological range; however, temperature pulses can phase-shift these rhythms. The phase response curve to heat pulses in the rat SCN in vitro is similar in shape to both the photic PRC for behavioral rhythms in rats (Honma et al., 1978; Gander and Lewis, 1983) and to the PRC to glutamate pulses administered to the rat SCN in vitro (Ding et al., 1994). There was also a positive linear relationship between heat pulse duration and phase-shift magnitude. These findings extend the principle of temperature compensation and similarity of light and temperature PRCs found in plants, bacte-

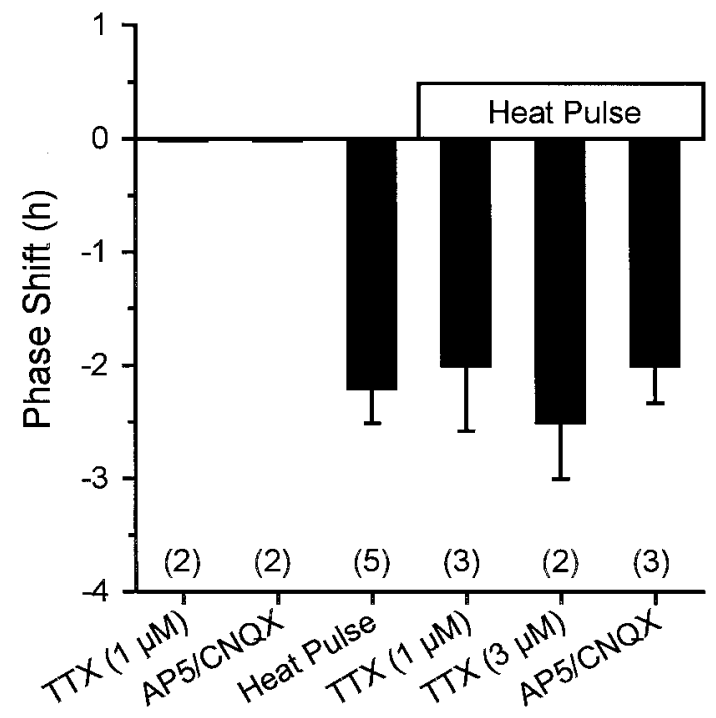

Figure 6. Mean $( \pm \mathrm{SE})$ phase delays produced by each drug treatment. Control groups are TTX $(1 \mu \mathrm{M})$, AP-5/CNQX, or the heat pulse applied alone. All other treatments were applied in the presence of the heat pulse. Numbers in parentheses indicate number of recording trials for each group. There were no significant differences among the three controls compared to untreated slices $(p>0.05)$ or among treatments coadministered with the heat pulse $(p>0.05)$.
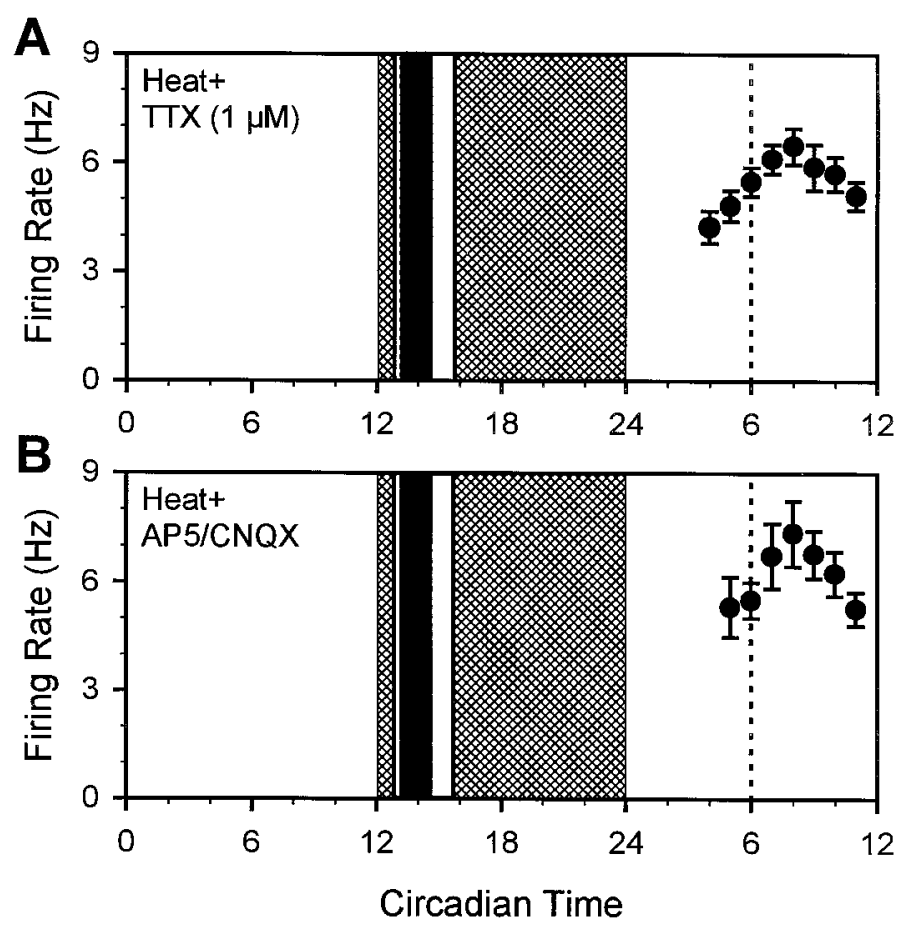

Figure 7. Representative recordings of neuronal rhythms after coapplication of a heat pulse at CT 14 with TTX $(1 \mu \mathrm{M})(A)$ or AP-5/CNQX $(B)$. Drugs were bath-applied to the tissue beginning $15 \mathrm{~min}$ before, and ending $45 \mathrm{~min}$ after, the heat pulse (Fig. 2). Vertical white bars indicate the onset and termination of drug applications, and black bars indicate the time of the heat pulse. Other symbols as in Figure 1.

ria, fungi, single-cell organisms, and insects to a homeothermic mammal. In a previous study, we found that circadian neuronal rhythms in the SCN of a hibernator were also temperaturecompensated (Ruby and Heller, 1996). The persistence of these 
features of circadian rhythms in the SCN of homeothermic and heterothermic mammals, and in pacemakers isolated from chick pinealocytes (Barrett and Takahashi, 1995) and hamster retinae (Tosini and Menaker, 1998), suggest that evolution of endothermy has not led to relaxed selection pressure for temperature compensation or sensitivity to thermal phase-shifting stimuli; rather, these properties have been conserved in circadian pacemakers from widely divergent taxonomic categories, including mammals.

\section{Temperature compensation in mammals}

A functional prerequisite for circadian pacemakers is that tau be temperature-compensated so that time keeping remains accurate over a range of physiological temperatures. Whereas $Q_{10}$ values for biological systems are generally between 2 and $3, Q_{10}$ values for tau range from 0.85 to 1.15 ( Pittendrigh, 1954; Hastings and Sweeney, 1957; Benson and Jacklett, 1977; Mattern et al., 1982; Menaker and Wisner, 1983; Berger et al., 1992; Kondo et al., 1993; Zatz et al., 1994; Barrett and Takahashi, 1995; Huang et al., 1995). This range of $Q_{10}$ values clearly represents a high degree of temperature compensation, although values at the extremes of this range allow for substantial effects of temperature on tau. For example, a temperature decrease of only $3^{\circ} \mathrm{C}$ shortens tau by 1.0-1.4 hr in cultured chick pinealocytes because that system has a $Q_{10}$ of $0.87-0.83$ (Zatz et al., 1994; Barrett and Takahashi, 1995). In contrast, the same temperature decrease shortens tau of neuronal rhythms in the rat SCN by only 6 min because that tau has a $Q_{10}$ of 0.99 .

In contrast to rhythm period, amplitude of the SCN neuronal rhythm in firing rate is highly temperature-sensitive in the rat. For example, peak firing rate in the rat SCN has a $Q_{10}$ of 2.7 when measured at 37 and $25^{\circ} \mathrm{C}$ (Ruby and Heller, 1996) and has a $Q_{10}$ of 1.8 when measured at 37 and $31^{\circ} \mathrm{C}$. $Q_{10}$ estimates depend on the range over which they are measured (Miller et al., 1994); rhythm amplitude in the rat SCN is more temperature-sensitive below, than above, $31^{\circ} \mathrm{C}$. Rhythm amplitude in the $\mathrm{SCN}$ is, however, much less sensitive to temperature in hibernators than it is in homeotherms. The $Q_{10}$ for neuronal rhythm amplitude in the SCN of the golden-mantled ground squirrel (Spermophilus lateralis) is only 1.3 , whereas it is 2.7 in rats, when measured over the same $12^{\circ} \mathrm{C}$ range (Ruby and Heller, 1996). Extrapolation of these data reveals that the SCN could continue to generate circadian rhythms of neuronal activity during hibernation $\left(T_{\mathrm{br}}=10^{\circ} \mathrm{C}\right)$, whereas neuronal rhythms are absent from the rat SCN when its temperature declines only to $25^{\circ} \mathrm{C}$ (cf., Ruby and Heller, 1996). The relative temperature compensation of rhythm amplitude in a hibernator suggests that this pacemaker output variable may have been adapted to serve as an important timing cue during deep torpor.

\section{Heat pulses as phase-shifting stimuli}

Even the most accurate temperature compensation observed in the SCN does not mean that the SCN is insensitive to temperature change. Phase shifts as great as $4 \mathrm{hr}$ were obtained in the present study when temperature was increased by only $3^{\circ} \mathrm{C}$ over an interval of $2 \mathrm{hr}$. A similar sensitivity to temperature pulses in spite of robust temperature compensation of tau has been reported for Drosophila (Pittendrigh, 1954; Edery et al., 1994; Huang et al., 1995). The magnitude of temperature pulses in the present study is within the range of those normally experienced by the mammalian brain. Circadian $T_{\mathrm{br}}$ rhythms in sedentary homeothermic rodents have an amplitude of $\sim 2.0^{\circ} \mathrm{C}$ (Abrams and
Hammel, 1965; Franken et al., 1992). Bursts of locomotor activity can produce increases in hypothalamic temperature $>2.0^{\circ} \mathrm{C}$ that are sustained for $>2 \mathrm{hr}$ in rats (Abrams and Hammel, 1965). Because these bursts of activity occur at the time of day when $T_{\mathrm{br}}$ is elevated above its daily mean, $T_{\mathrm{br}}$ may change by $3-4^{\circ} \mathrm{C}$ over the course of a day in an active rat.

In addition to activity, sleep state transitions and torpor are also associated with changes in $T_{\mathrm{br}}$. In the pocket mouse (Perognathus longimembris), $T_{\mathrm{br}}$ decreases by as much as $1.0^{\circ} \mathrm{C}$ during transitions from slow wave sleep to REM sleep (Walker et al., 1983). Changes in $T_{\mathrm{br}}$ are even more pronounced when these animals become torpid. These hibernators arouse from torpor every 1-3 d during the hibernation season (Bartholemew and Cade, 1957; French, 1977). Arousals occur at intervals that are multiples of nearly $24 \mathrm{hr}$ in animals housed in constant darkness. A decrease in $T_{\mathrm{a}}$ of $11^{\circ} \mathrm{C}$ shortened the period of the arousal rhythm by $>1$ hr (Lindberg et al., 1971). Furthermore, these mice entrain to temperature cycles in which the two phases of the cycle differ by only $1.5^{\circ} \mathrm{C}$. Their activity rhythms also can be phaseshifted several hours by brief increases in $T_{\mathrm{a}}$ (Lindberg and Hayden, 1974); the PRC to temperature pulses is similar to the photic PRC (Lindberg and Hayden, 1974). One possible explanation for these effects may be that changes in $T_{\mathrm{a}}$ are accompanied by changes in SCN temperature. During torpor, $T_{\mathrm{br}}$ is maintained only slightly above $T_{\mathrm{a}}$, therefore, a decline in $T_{\mathrm{a}}$ will be followed by a decline in $T_{\mathrm{br}}$ while the animal is torpid, and by increases in $T_{\mathrm{br}}$ when $T_{\mathrm{a}}$ increases. Thus, changes in $T_{\mathrm{br}}$ associated with torpor may act directly on the SCN to influence circadian timing rather than through thermal afferent pathways to the SCN.

\section{Cellular mechanisms of phase delays by heat and light}

The PRC obtained in this study is quite similar in shape to photic PRCs obtained from several mammalian species (Johnson, 1990) and to the PRC to glutamate pulses administered to the SCN in vitro (Ding et al., 1994). All of these PRCs have phase delay and advance regions in early and late subjective night, respectively, and are relatively unresponsive during midsubjective day. The strong similarity between light, heat, and glutamate PRCs suggests that these stimuli share a final common pathway that resets the pacemaker in the SCN. One view of the cellular mechanism by which photic information is transduced to the SCN suggests that activation of retinal photoreceptors results in the release of glutamate from terminals in the retinohypothalamic tract onto SCN neurons (Ding et al., 1994). Glutamate then binds to NMDA receptors on SCN cells and causes a rise in intracellular calcium concentration (Ding et al., 1994). The calcium rise stimulates nitric oxide synthase and the production of nitric oxide that ultimately results in phase shifts of behavioral rhythms (Ding et al., 1994). This is unlikely the sole resetting mechanism activated by glutamate release because non-NMDA agonists also phaseshift the SCN in a manner similar to NMDA receptor activation (Shibata et al., 1994) and also because the role of metabotropic glutamate receptors in pacemaker resetting has not been evaluated. Nevertheless, it is clear that glutamate release is critically involved in transducing phase shifts by light, regardless of the downstream signaling mechanisms. Therefore, we tested the hypothesis that heat pulses used in this study phase delayed the pacemaker by activating ionotropic glutamate receptors on SCN cells. It was possible that heat could increase glutamate release from synaptic vesicles that remain in the axon terminals of tissue slices or that heat might alter the kinetics between glutamate and its receptors. Because coapplication of $\mathrm{AP}-5 / \mathrm{CNQX}$ failed to 
block heat-induced phase delays, we concluded that phase shifts in response to heat pulses were not mediated by ionotropic glutamate receptors because these drugs block NMDA and nonNMDA receptors, respectively. We considered blocking metabotropic glutamate receptors, however, it is unlikely that we could effectively block all such receptors with currently available antagonists.

This study has demonstrated that the effects of heat pulses on pacemaker phase do not require action potential-dependent neurotransmitter release nor are they the result of increased cellular metabolism associated with changes in action potential frequency during the heat pulse. The neurotoxin TTX blocks sodiumdependent action potentials by binding to sodium channels in axonal membranes (Hille, 1992). The TTX experiments suggest that heat pulses phase-shift pacemakers within individual cells and that phase delays do not depend on neuronal interactions via action potential-dependent neurotransmitter release. Furthermore, blocking action potentials eliminates the primary mechanism of neurotransmitter release at axon terminals and prevents cellular increases in metabolism associated with action potential propagation (Hille, 1992). The failure of TTX to block heatinduced phase delays suggests that such phase shifts are probably not the result of metabolic changes associated with temperature changes in SCN cells.

We propose that heat pulses most likely phase-shift rhythms by acting on clock mechanisms within individual cells rather than by activating glutamatergic signal transduction pathways or by altering intercellular signaling or rates of cellular metabolism. The cellular mechanism by which temperature phase-shifts SCN rhythms may be similar to phase-shifting mechanisms in Neurospora. In that system, light and temperature PRCs are similar (Francis and Sargent, 1979), and both stimuli affect transcription of the frq gene and translation of the FRQ protein (Liu et al., 1998). The circadian rhythm of FRQ protein translation is a temperature-dependent process, whereas frq transcription is not. Circadian phase after a heat pulse is thought to be determined by the way the relative amounts of $f r q$ and FRQ are interpreted at a particular temperature (Liu et al., 1998). If circadian phase is encoded in the SCN by gene products involved in rhythm generation, then heat pulses may act to alter the amounts of proteins, such as PER and TIM, that are involved in mammalian circadian rhythm generation (Shigeyoshi et al., 1997; Bae et al., 1998).

\section{REFERENCES}

Abrams R, Hammel HT (1965) Cyclic variations in hypothalamic temperature in unanesthetized rats. Am J Physiol 208:698-702.

Aschoff J, Tokura H (1986) Circadian activity rhythms in squirrel monkeys: entrainment by temperature cycles. J Biol Rhythms 1:91-99.

Bae K, Lee C, Sidote D, Chuang KY, Edery I (1998) Circadian regulation of a Drosophila homolog of the mammalian Clock gene: PER and TIM function as positive regulators. Mol Cell Biol 18:6142-6151.

Barrett RK, Takahashi JS (1995) Temperature compensation and temperature entrainment of the chick pineal cell circadian clock. J Neurosci 15:5681-5692.

Bartholemew GA, Cade TJ (1957) Temperature regulation, hibernation, and aestivation in the little pocket mouse, Perognathus longimembris. J Mammal 38:60-72.

Belousov AB, van den Pol AN (1997) Local synaptic release of glutamate from neurons in the rat hypothalamic arcuate nucleus. J Physiol (Lond) 499:747-761.

Benson JA, Jacklett JW (1977) Circadian rhythm of output from neurones in the eye of Aplysia I. effects of deuterium oxide and temperature. J Exp Biol 70:151-166.

Berger S, Dirk J, von Lindern L, Wolff D, Mergenhagen D (1992) Temperature dependency of circadian period in a single cell (Acetabularia). Bot Acta 105:382-386.
Ding JM, Chen D, Weber ET, Faiman LE, Rea MA, Gillette MU (1994) Resetting of the biological clock: mediation of nocturnal circadian shifts by glutamate and NO. Science 266:1713-1717.

Edery I, Rutila JE, Rosbash M (1994) Phase shifting of the circadian clock by induction of the Drosophila period protein. Science 263:237-240.

Erkert HG, Rothmund E (1981) Differences in temperature sensitivity of the circadian systems of homeothermic and heterothermic neotropical bats. Comp Biochem Physiol 68A:383-390.

Francis AJP, Coleman GJ (1988) The effects of ambient temperature cycles upon circadian running and drinking activity in male and female laboratory rats. Physiol Behav 43:471-477.

Francis AJP, Coleman GJ (1990) Ambient temperature cycles entrain the free-running circadian rhythms of the stripe-faced dunnart, Sminthopsis macroura. J Comp Physiol [A] 167:357-362.

Francis AJP, Coleman GJ (1997) Phase response curves to ambient temperature pulses in rats. Physiol Behav 62:1211-1217.

Francis CD, Sargent ML (1979) Effects of temperature perturbations on circadian conidiation in Neurospora. Plant Physiol 64:1000-1004.

Franken P, Tobler I, Borbély AA (1992) Sleep and waking have a major effect on the 24-hr rhythm of cortical temperature in the rat. J Biol Rhythms 7:341-352.

French AR (1977) Periodicity of recurrent hypothermia during hibernation in the pocket mouse, Perognathus longimembris. J Comp Physiol [B] 115:87-100.

Gander PH, Lewis RD (1983) Phase-resetting action of light on the circadian activity rhythm of Rattus exulans. Am J Physiol 245:R10-R17.

Gibbs FP (1981) Temperature dependence of rat circadian pacemaker. Am J Physiol 241:R17-R20.

Gibbs FP (1983) Temperature dependence of the hamster circadian pacemaker. Am J Physiol 244:R607-R610.

Gillette MU (1991) SCN electrophysiology in vitro: rhythmic activity and endogenous clock properties. In: Suprachiasmatic nucleus: the mind's clock (Klein DC, Moore RY, Reppert SM, eds), pp 125-143. New York: Oxford UP.

Goldman BD, Goldman SL, Riccio AP, Terkel J (1997) Circadian patterns of locomotor activity and body temperature in blind mole-rats, Spalax ehrenbergi. J Biol Rhythms 12:348-361.

Hastings JW, Sweeney BM (1957) On the mechanism of temperature independence in a biological clock. Proc Natl Acad Sci USA 43:804-811.

Hatton GI, Doran AD, Salm AK, Tweedle CD (1980) Brain slice preparation: hypothalamus. Brain Res Bull 5:405-414.

Hille B (1992) Ionic channels of excitable membranes. Sunderland, MA: Sinauer.

Honma K, Katabami F, Hiroshige T (1978) A phase response curve for the locomotor activity rhythm of the rat. Experientia 34:1602-1603.

Huang ZJ, Curtin KD, Rosbash M (1995) PER protein interactions and temperature compensation of a circadian clock in Drosophila. Science 267:1169-1172.

Johnson CH (1990) An atlas of phase response curves for circadian and circatidal rhythms. Nashville: Vanderbilt University.

Kondo T, Strayer CA, Kulkarni RD, Taylor W, Ishiura M, Golden SS, Johnson CH (1993) Circadian rhythms in prokaryotes: luciferase as a reporter of circadian gene expression in cyanobacteria. Proc Natl Acad Sci USA 90:5672-5676.

Lindberg RG, Hayden P (1974) Thermoperiodic entrainment of arousal from torpor in the little pocket mouse, Perognathus longimembris. Chronobiologica 1:356-361.

Lindberg RG, Gambino JJ, Hayden P (1971) Circadian periodicity of resistance to ionizing radiation in the pocket mouse. In: Biochronometry (Menaker M, ed), pp 169-185. Washington, DC: National Academy of Sciences.

Liu Y, Merrow M, Loros JJ, Dunlap JC (1998) How temperature changes reset a circadian oscillator. Science 281:825-829.

Mattern DL, Forman LR, Brody S (1982) Circadian rhythms in Neurospora crassa: a mutation affecting temperature compensation. Proc Natl Acad Sci USA 79:825-829.

Menaker M, Wisner S (1983) Temperature-compensated clock in the pineal of Anolis. Proc Natl Acad Sci USA 80:6119-6121.

Miller JD, Cao VH, Heller HC (1994) Temperature effects on neuronal activity in the suprachiasmatic nucleus of hibernators and nonhibernators. Am J Physiol 266:R1259-R1266.

Nakashima H (1987) Comparison of phase shifting by temperature of 
wild type Neurospora crassa and the clock mutant, rrq- $^{-7}$. J Interdiscipl Cycle Res 18:1-8.

Njus D, McMurry L, Hastings JW (1977) Conditionality of circadian rhythmicity: synergistic action of light and temperature. J Comp Physiol [B] 117:335-344.

Pittendrigh CS (1954) On temperature independence in the clock system controlling emergence time in Drosophila. Proc Natl Acad Sci USA 40:1018-1029.

Pittendrigh CS (1960) Circadian rhythms and the circadian organization of living systems. Cold Spring Harb Symp Quant Biol 25:159-184.

Pohl H (1998) Temperature cycles as zeitgeber for the circadian clock of two burrowing rodents, the normothermic antelope ground squirrel and the heterothermic Syrian hamster. Biol Rhythm Res 29:311-325.

Rawson KS (1960) Effects of tissue temperature on mammalian activity rhythms. Cold Spring Harb Symp Quant Biol 25:105-113.

Rosenwasser AM (1988) Behavioral neurobiology of circadian pacemakers: a comparative perspective. Prog Psychobiol Physiol Psych 13:155-226.

Ruby NF, Heller HC (1996) Temperature sensitivity of the suprachiasmatic nucleus of ground squirrels and rats in vitro. J Biol Rhythms 11:127-137.

Rusak B, Zucker I (1979) Neural regulation of circadian rhythms. Physiol Rev 59:449-526.

Shibata S, Moore RY (1993) Tetrodotoxin does not affect circadian rhythms in neuronal activity and metabolism in rodent suprachiasmatic nucleus in vitro. Brain Res 606:259-266.

Shibata S, Watanabe A, Hamada T, Ono M, Watanabe S (1994) $N$-methyl-D-aspartate induces phase shifts in circadian rhythm of neuronal activity of rat SCN in vitro. Am J Physiol 267:R360-R364.
Shigeyoshi Y, Taguchi K, Yamamoto S, Takekida S, Yan L, Tei H, Moriya T, Shibata S, Loros JJ, Dunlap JC, Okamura H (1997) Lightinduced resetting of a mammalian circadian clock is associated with rapid induction of the mPer1 transcript. Cell 91:1043-1053.

Tokura H, Aschoff J (1983) Effects of temperature on the circadian rhythm of pig-tailed macaques Macaca nemestrina. Am J Physiol 245:R800-R804.

Tosini G, Menaker M (1998) The tau mutation affects temperature compensation of hamster retinal circadian oscillators. NeuroReport 9:1001-1005.

Underwood H (1990) The pineal and melatonin: regulators of circadian function in lower vertebrates. Experientia 46:120-128.

Walker JM, Walker LE, Harris DV, Berger RJ (1983) Cessation of thermoregulation during REM sleep in the pocket mouse. Am J Physiol 244:R114-R118.

Walsh IB, van den Berg RJ, Marani E, Rietveld WJ (1992) Spontaneous and stimulated firing in cultured rat suprachiasmatic neurons. Brain Res 588:120-131.

Wilkins MB (1983) The circadian rhythm of carbon-dioxide metabolism in Brophyllum: the mechanism of phase-shift induction by thermal stimuli. Planta 157:471-480.

Zatz M, Lange GD, Rollag MD (1994) What does changing the temperature do the melatonin rhythm in cultured chick pineal cells? Am J Physiol 266:R50-R58.

Zimmerman WF, Pittendrigh CS, Pavlidis T (1968) Temperature compensation of the circadian oscillation in Drosophila pseudoobscura and its entrainment by temperature cycles. J Insect Physiol 14:669-684. 